\title{
Nutrient reference value: non-communicable disease endpoints—a conference report
}

\author{
J. R. Lupton ${ }^{1}$ J. B. Blumberg ${ }^{2}$ M. L'Abbe ${ }^{3} \cdot$ M. LeDoux ${ }^{4} \cdot$ H. B. Rice ${ }^{5} \cdot$ \\ C. von Schacky ${ }^{6} \cdot$ A. Yaktine $^{7} \cdot$ J. C. Griffiths ${ }^{8}$
}

Published online: 16 March 2016

(C) The Author(s) 2016. This article is published with open access at Springerlink.com

\begin{abstract}
Nutrition is complex-and seemingly getting more complicated. Most consumers are familiar with "essential nutrients," e.g., vitamins and minerals, and more recently protein and important amino acids. These essential nutrients have nutrient reference values, referred to as dietary reference intakes (DRIs) developed by consensus committees of scientific experts convened by the Institute of Medicine of the National Academy of Sciences, Engineering, and Medicine and carried out by the Food and Nutrition Board. The DRIs comprise a set of four nutrient-based reverence values, the estimated average requirements, the recommended dietary allowances (RDAs), the
\end{abstract}

Disclaimer: Any views not attributed to an IOM report are those of the author and do not necessarily represent the views of The National Academies of Sciences, Engineering, and Medicine.

This is the sixth CRN-International conference report. Previous conference reports were published in Regulatory Toxicology and Pharmacology [58], and for the last 4 years, in the European Journal of Nutrition [1, 2, 36, 39].

\section{J. C. Griffiths}

jgriffiths@crnusa.org

1 Emeritus, Texas A\&M University, College Station, TX, USA

2 Tufts University, Boston, MA, USA

3 University of Toronto, Toronto, ON, Canada

4 Natural Alternatives International, Inc., San Marcos, CA, USA

5 Global Organization for EPA and DHA Omega-3s, Salt Lake City, UT, USA

6 University of Munich, Munich, Germany

7 The National Academies of Sciences, Engineering, and Medicine, Washington, DC, USA

8 Council for Responsible Nutrition, Washington, DC, USA adequate intakes and the tolerable upper intake levels for micronutrient intakes and an acceptable macronutrient distribution range for macronutrient intakes. From the RDA, the US Food and Drug Administration (FDA) derives a labeling value called the daily value (DV), which appears on the nutrition label of all foods for sale in the US. The DRI reports do not make recommendations about whether the DV labeling values can be set only for what have been defined to date as "essential nutrients." For example, the FDA set a labeling value for "dietary fiber" without having the DV. Nutrient reference values-requirements are set by Codex Alimentarius for essential nutrients, and regulatory bodies in many countries use these Codex values in setting national policy for recommended dietary intakes. However, the focus of this conference is not on essential nutrients, but on the "nonessential nutrients," also termed dietary bioactive components. They can be defined as "Constituents in foods or dietary supplements, other than those needed to meet basic human nutritional needs, which are responsible for changes in health status (Office of Disease Prevention and Health Promotion, Office of Public Health and Science, Department of Health and Human Services in Fed Regist 69:55821-55822, 2004).” Substantial and often persuasive scientific evidence does exist to confirm a relationship between the intake of a specific bioactive constituent and enhanced health conditions or reduced risk of a chronic disease. Further, research on the putative mechanisms of action of various classes of bioactives is supported by national and pan-national government agencies, and academic institutions, as well as functional food and dietary supplement manufacturers. Consumers are becoming educated and are seeking to purchase products containing bioactives, yet there is no evaluative process in place to let the public know how strong the science is behind the benefits or the quantitative amounts needed to 
achieve these beneficial health effects or to avoid exceeding the upper level (UL). When one lacks an essential nutrient, overt deficiency with concomitant physiological determents and eventually death are expected. The absence of bioactive substances from the diet results in suboptimal health, e.g., poor cellular and/or physiological function, which is relative and not absolute. Regrettably at this time, there is no DRI process to evaluate bioactives, although a recent workshop convened by the National Institutes of Health (Options for Consideration of Chronic Disease Endpoints for Dietary Reference Intakes (DRIs); March 10-11, 2015; http://health.gov/dietaryguidelines/dri/) did explore the process to develop DVs for nutrients, the lack of which result in increased risk of chronic disease (non-communicable disease) endpoints. A final report is expected soon. This conference (CRN-International Scientific Symposium; "Nutrient Reference Value-Non-Communicable Disease (NRV-NCD) Endpoints," 20 November in Kronberg, Germany; http://www.crn-i.ch/2015symposium/) explores concepts related to the Codex NRV process, the public health opportunities in setting NRVs for bioactive constituents, and further research and details on the specific class of bioactives, n-3 long-chain polyunsaturated fatty acids (also termed omega-3 fatty acids) and their constituents, specifically docosahexaenoic acid and eicosapentaenoic acid.

Keywords Bioactives $\cdot$ Nutrient reference values . nonessential nutrients $\cdot$ Adequate intake $\cdot \mathrm{n}-3$ longchain polyunsaturated fatty acids $\cdot$ Omega-3 fatty acids . Docosahexaenoic acid (DHA) - Eicosapentaenoic acid (EPA)

\section{Introduction}

This scientific symposium, to which these proceedings contribute this conference report, again ask the question "Is it important to have a dietary reference intake- (DRI-) like [also termed nutrient reference value- (NRV-) like] process for the evaluation of bioactives?" Research continues to suggest that there are real benefits to human public health to be obtained from including bioactive constituents in the diet and/or from dietary supplements. Past symposia have looked at common bioactives, including flavanols from tea and chocolate; lycopene and other tomato carotenoids; lutein and zeaxanthin and soybean isoflavones isolated from plants and animals (fish oil) $[3,39]$. The wide range of academic institutions, from virtually every part of the globe, confirm the seriousness to which researchers are exploring the biochemical and biophysiological processes attributed to these substances.

Consumers deserve clarity and transparency regarding bioactive content and access to reliable information on products. But how is the public able to understand the strength (and/or limitations) of the science supporting the putative benefits-and even if the link between intake and disease risk reduction is confirmed and advertised and accepted, how much is the right amount to consume? Too little and the desired effect might not be realized-too much and overt toxicity may develop. An evaluative process was proposed 2 years ago at this same scientific symposium (see Table 1), and it continues to be discussed and evaluated as a framework approach.

If the science base was translated into a recommended intake value, assessments could be made as to whether or not populations or specific age groups were meeting that recommendation and consumers would know the overall contribution of a food or beverage or dietary supplement to achieving the recommended amount.

If an authoritative body such as the Institute of Medicine IOM or the Codex Alimentarius Commission would establish reference values for bioactives that promote health or contribute to a reduction in risk of non-communicable disease endpoint (NRV-NCD), then the bioactive of merit would become part of national and international nutrition policy and be used to bolster public health initiatives. For example, in the US, with a realistic DRI value, intake information as incorporated into and referenced by the National Health and Nutrition Examination Survey (NHANES) would allow the government agencies and researchers to understand the amount of nutrient(s) being consumed and be able to address "at risk" low nutrient (bioactive) consumers. Having a DRI, or even just an element such as the adequate intake (AI), would assist responsible authorities in developing education and messaging to the consumers at risk or at borderline for the health-promoting, disease-reducing benefits of specific bioactives. It is the stated objective of the US Dietary Guidelines for Americans that if one follows all of the recommendations of the guidelines, one will automatically meet the DRI values for nearly all of the nutrients [45]. Thus, dietary guidance is another important way that information on bioactives with substantial science behind their efficacy could be transmitted to consumers.

In the twenty-first century, advances in research of healthgiving nutrients is demonstrating promise in achieving reductions in morbidity and mortality in formerly high-risk populations. What regulators do with this research is of paramount importance. The time for parochialism and market protectionism thinly disguised as bona fide barriers to commercial trade based on unsound reasoning are over. The regulatory and scientific communities need to revisit their historical biases in favor of a more rational outcome objective.

\section{Setting an intake value for bioactives}

There are multiple reasons why a framework for the evaluation of bioactives should be considered. The primary 


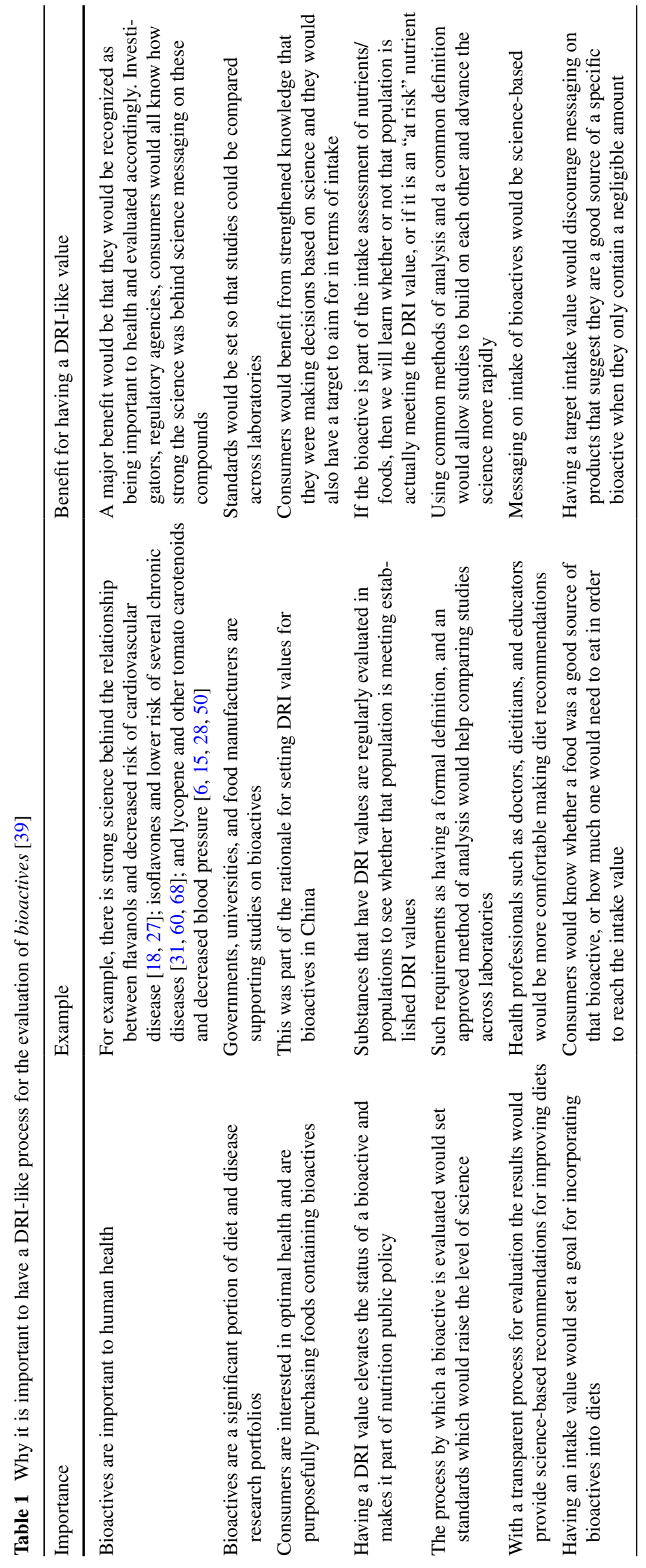


reason is to promote public health (i.e., "What is an efficacious amount?"; "How strong is the science?"; "What are potential adverse effects?"). Would setting an intake value for a bioactive fit the DRI paradigm?

Food is now viewed by many as a source of substances that provide robust cell/tissue functions or optimal health rather than just to protect against nutrient deficiency diseases. It is important to provide consumers with information as to how strong the science is behind purported benefits, how much they would need to eat to achieve these benefits, and how much is too much.

What are the major issues involved in setting an intake value for bioactives? First, bioactives are different from essential nutrients in that the absence of the bioactive in the diet does not result in a deficiency disease specific to that bioactive. In contrast, if an essential nutrient is absent from the diet one will get a deficiency-microcytic anemia for lack of iron, scurvy for vitamin $\mathrm{C}$, beriberi for thiamin, etc. This means that an intake value for a bioactive cannot be based on a deficiency disease; instead, alternative endpoints for intake values are needed. Some have suggested basing intake values on endpoints characterizing "health" rather than lack of disease, which is philosophically attractive, but this is still a developing science base. Another type of endpoint, appropriate for bioactives might be a beneficial physiological effect such as blood pressure or vascular reactivity. This is an important area of research but does not have much traction in the US. A third alternative is basing the endpoint on decreased risk of disease. This has elicited some traction for the US/Canada DRI Government subcommittee for DRIs. Also, much of the research done with bioactives is targeted at decreased risk of non-communicable diseases (NCDs). In fact, using chronic disease endpoints to determine intake values was a major recommendation coming from two key IOM publications [25, 65]. In the process, an intake value (AI) was developed and used as the intake value for several nutrients. The AI is defined as "The recommended average daily intake level based on observed or experimentally determined approximations or estimates of nutrient intake by a group (or groups) of apparently healthy people that are assumed to be adequate-used when a recommended dietary allowance (RDA) cannot be determined." If an intake value for a bioactive were to be based on a chronic disease endpoint, it would likely be an AI rather than an RDA. In part this is because the absolute risk of most chronic diseases applies to only a portion of the population, rather than the entire population for a deficiency disease which is nutrient-specific (e.g., scurvy for vitamin C). Chronic diseases are not nutrient specific, but multifactorial.

\section{The DRI process: strengths and limitations of evidence}

The process of setting standardized nutrient intake values was formalized in the US more than 75 years ago in response to widespread nutrient deficiency diseases in the general population. Following establishment of the RDAs, the prevalence of frank nutrient deficiency disease diminished; however, in the subsequent decades, risk of a range of diet-related chronic diseases increased. Cardiovascular disease, including stroke and coronary artery disease, obesity, type 2 diabetes, and cancer are now predominant public health concerns. In response to the 1988 Surgeon General's Report [62], the 1989 Diet and Health Report [46], and a 1994 IOM Report [23], reduction in risk of chronic disease, identification of food components related to health benefits, and evaluation of risk from both deficiency and excess were identified as relevant concerns to be addressed in revising the RDAs. The outcome was a framework for what would become the DRIs. The new paradigm was based on reducing both the risk of inadequacy of nutrient intakes and the risk of adverse outcomes from excessive intakes using a risk assessment model. Today, the goal is to understand how the DRI paradigm can be applied to identification of nutrients and other food components to achieve reduction in relative risk of diet-related chronic disease. A number of factors limit use of the current DRI process to identify intake levels sufficient for chronic disease risk reduction at the population level. Major barriers include: population variability in disease risk, lack of dose-response relationships for health outcomes, identifying upper level intake thresholds, and insufficient evidence to support setting DRIs for nutrients with chronic disease endpoints. For five nutrients identified for DRIs, limitations in available evidence for reduction of chronic disease risk led to an AI rather than an RDA across all age categories. The challenge moving forward is to determine whether or how the DRI process can be adapted to nutrients such as the "nonessential" nutrients, EPA and DHA found in omega-3 fatty acids that have implications for reduction in risk of chronic disease. That will require consideration of important research gaps, including biomarker validation studies, determining safe and effective upper and lower nutrient intake levels, nutrient interactions with other substances in foods, and determination of nutrient requirements across age groups.

\section{Evidence-based nutrition: the problem of proof}

Over the last decade, randomized clinical trials (RCTs) of dietary supplements and nutritional interventions for major disease entities have largely resulted in null or 
negative outcomes despite positive results from in vitro, animal model, and observational studies. Because RCTs have traditionally been accepted as the "gold standard" for establishing cause-and-effect relationships, these studies have led to skepticism about the importance of specific nutrients or nutrient combinations in health and disease by clinicians, researchers, funding agencies, and the public. Nonetheless, the foundation of RCTs in evidence-based medicine has now been wholly adopted in the creation of nutrition and science policy despite distinct differences between the evidence needed for testing of drugs versus that needed for the development of nutrient requirements and dietary guidance. There is a need to better define the types of evidence necessary for developing dietary guidelines and recommending nutrient interventions than that used for drug efficacy and safety. For example, unlike drugs, nutrients and other dietary bioactive components work in complex networks, are often under homeostatic control, and cannot be contrasted to a true placebo group. Although RCTs present one approach toward understanding the efficacy of nutrient interventions, the innate complexities of nutrient actions and interactions cannot always be adequately addressed through a single research design. Further, action to define requirements for nutrients and dietary bioactive components or to recommend dietary guidelines to promote health and/or reduce the risk of chronic disease should be taken at a level of confidence that is different from that needed in the evaluation of drug efficacy and safety in the treatment of disease. Moreover, in assessing the balance between the potential harm of making or not making a nutrient or dietary recommendation, appropriate educational strategies will be necessary to convey the varying levels of the strength of the evidence. Advancing evidence-based nutrition from its current version to one based upon more relevant and realistic criteria will depend upon research approaches that include RCTs but go beyond them $[4,55,56]$.

\section{Omega-3 fatty acid (EPA/DHA) research}

Fatty acids are necessary components of cell membranes, and changes in fatty acid composition of these membranes can modulate cell function. While some fatty acids, like saturated or some mono-unsaturated fatty acids can be formed by the human body, others, like the omega- 3 fatty acid alpha-linolenic or the omega- 6 fatty acid linoleic, cannot. It was thought that longer chain polyunsaturated fatty acids (PUFAs) of both the omega- 3 and omega- 6 type could be formed in humans from the shorter chain fatty acids mentioned. This, however, does not occur in quantities sufficient to maintain optimal function of the respective cells (e.g., brain, heart) [7, 51]. Therefore, some PUFAs, especially eicosapentaenoic acid (EPA) or docosahexaenoic acid (DHA), need to be obtained from the diet.

Diet was the traditional focus of research in nutrition. However, results obtained with food frequency questionnaires were recently found to be physiologically implausible and their validity thus extremely limited [2]. Moreover, fatty acid compositions of dietary components change, and fatty acid uptake from the gut and incorporation into cells varies inter-individually by a factor of 13 [30]. To circumvent these three levels of uncertainty, erythrocyte $\mathrm{EPA}+\mathrm{DHA}$ is being used as a biomarker for marine omega-3 fatty acids [64]. Erythrocyte EPA + DHA has a low biological variability and correlates with EPA + DHA in all cell types studied so far, and a standardized analytical procedure (HS-Omega-3 Index $^{\circledR}$ ) is available, which is the basis of some 174 publications international journals and $>50$ ongoing research projects, some of which are considered below [29, 35, 63, 64, 71].

In Western countries, including Canada or Germany, diseases like cardiovascular disease, major depression, or cognitive impairment have a high prevalence, and more than three quarters of the population have an HS-Omega- $3^{\circledR}$ Index below the target healthy range of $8-11 \%[35,64]$. By current standards of the American Heart Association, low levels of EPA + DHA in erythrocytes are a cardiovascular risk factor [64]. Due to issues in methodology uncovered by measuring EPA + DHA in erythrocytes, pertinent large intervention trials had neither positive nor negative, i.e., null outcomes [64]. Because this fact hampers widespread use of EPA + DHA in cardiovascular prevention, a new generation of large trials with clinical endpoints is needed.

Low levels of erythrocyte EPA + DHA have been found in individuals with suboptimal brain development, attention deficit-hyperkinetic disorder, major depression, or issues in complex brain function, like memory, executive function and others in all age groups studied so far. In all of these impairments of cognitive function, most randomized controlled intervention trials demonstrated positive effects of EPA + DHA supplementation, quantitatively correlating with the increase of EPA + DHA in erythrocytes, if measured. Thus, a causal role of EPA + DHA has been identified in the brain function issues mentioned. Moreover, consistent with observational studies showing EPA + DHA intake or status at suboptimal levels in Western countries, these data support the interpretation that, in Western countries (but not in countries like Japan or Korea), a widespread deficit of EPA + DHA intake exists.

Other health issues for which positive effects of increased intake or an elevation of erythrocyte EPA + DHA have been demonstrated are muscle function, osteoporosis, rheumatoid arthritis, non-alcoholic fatty liver, and others. Of note, "age-related" deterioration of brain and muscle 
function can be slowed by EPA + DHA, again supporting the interpretation of a widespread deficit in Western countries $[57,67]$.

\section{Scientific basis for a public health recommendation for EPA/DHA}

Globally, consumption of the omega- 3 fatty acids, EPA and DHA is inadequate for cardiovascular disease risk reduction. In 2010, the attributable burden of a diet low in seafood omega-3s (rich in EPA and DHA) was $1.1 \%$ of global disability-adjusted life years (DALYs), a measure of overall disease burden, expressed as the number of years lost due to ill health, disability, or early death [38]. That same year, diets low in EPA + DHA accounted for 1,389,896 deaths, up from 1,043,085 in 1990 [38]. Given the recent commencement of work to establish a NRV-NCD for EPA + DHA, the totality of the scientific evidence supporting the cardiovascular benefits of EPA/DHA is important to consider [9].

There is a long history of research demonstrating that EPA and DHA have cardioprotective benefits. This research includes both observational studies and RCTs. In contrast to earlier investigations [5, 21, 70]; GISSI-HF Investigators, [20] demonstrating that consumption of fatty fish or EPA/DHA supplements have clear benefits for cardiovascular health, some recent studies [19, 33, 40]; ORIGIN $[49,52,53,59]$ have not demonstrated significant effects of EPA and DHA on cardiovascular disease (CVD) risk/ events.

Potential reasons why recent research has resulted in null outcomes include, but are not limited to, the following: insufficient dose of omega-3s, treatment duration too short, maintenance on aggressive cardiovascular drug treatment, too few subjects, use of composite endpoints, higher background omega-3 intake, and subjects with such advanced CVD that you wouldn't expect a benefit at such a late stage of the disease [22, 26, 41, 64, 69]. Given the preponderance of positive research in the past, the recent null results may be considered anomalies. The reality is that the evidence for many outcomes is very consistent.

For example, the evidence that EPA/DHA reduce the risk of cardiac death is strong. Between 2008 and 2014, 11 meta-analyses were published on the cardiovascular benefits of EPA/DHA. Each of the 11 meta-analyses consistently demonstrated a statistically, not to mention clinically, significant reduction (9-32\%) in the risk for cardiac death $[8,10,12,32,34,37,42,54,61,66,72]$.

In addition to the consistency of results associated with EPA/DHA and cardiac death risk reduction across a wide range of doses, EPA/DHA consistently provide a statistically significant reduction in blood pressure, a biomarker for coronary heart disease. In 2014, a comprehensive metaanalysis of 70 RCTs on the effects of EPA and DHA (from seafood, fortified foods, or dietary supplements) on blood pressure was published [43]. The study included trials with subjects with normal blood pressure and those with hypertension but not taking blood pressure-lowering medications. Among all subjects, the average decrease in systolic blood pressure (SBP) and diastolic blood pressure (DBP) was 1.52 and $0.99 \mathrm{~mm} \mathrm{Hg}$, respectively. Among subjects with high blood pressure, the average decrease in SBP and DBP was 4.51 and $3.05 \mathrm{~mm} \mathrm{Hg}$, respectively. The findings were considered even more dramatic when compared to reductions achieved through commonly recommended lifestyle changes like reducing intake of dietary sodium (3.6 $\mathrm{mm} \mathrm{Hg}$ ), increasing physical activity $(4.6 \mathrm{~mm} \mathrm{Hg}$ ), and decreasing alcohol consumption $(3.8 \mathrm{~mm} \mathrm{Hg})$ [13].

To establish a NRV, it is important to consider not only the efficacy, but the safety of the nutrient(s) in question. According to the Codex Guidelines on Nutrition Labelling, the establishment of general population NRVs should take into account upper levels (ULs) established by the Food and Agriculture Organization of the United Nations (FAO) and the World Health Organization (WHO) or other recognized authoritative scientific bodies [11]. For over 25 years, every known comprehensive safety evaluation on EPA/DHA has concluded that there is insufficient evidence to establish an UL for EPA/DHA because of a lack of observed untoward outcomes [24, 44]; Norwegian Scientific Committee for Food Safety, [14, 47].

In the absence of a UL, FAO/WHO introduced the highest observed intake (HOI) level [16]. "The HOI is derived only when no adverse health effects have been identified. It is the highest level of intake observed or administered as reported within (a) study(ies) of acceptable quality." In order to establish a NRV for EPA + DHA, the concept of a HOI will need to be accepted by Codex. Recent safety evaluations $[14,47]$ concluding the absence of sufficient evidence to establish an UL for EPA + DHA noted no safety concerns with levels from 5.0 to $6.9 \mathrm{~g}$ per day-levels at least $20 \times$ higher than the FAO minimum recommended intake of $250 \mathrm{mg} /$ day [17].

\section{Summary, conclusion, and next steps}

Each bioactive is unique, and the scientific underpinnings to the strength (breadth and depth) of scientific data vary. Some bioactives benefit from many decades of research in support of a purported reduction in disease risk. Others are overnight sensations, coming from traditional medicines in developing countries and regions. A framework approach must be able to differentiate and apply a tiered approach to the evaluation. Dr Lupton has proposed that there exists, 


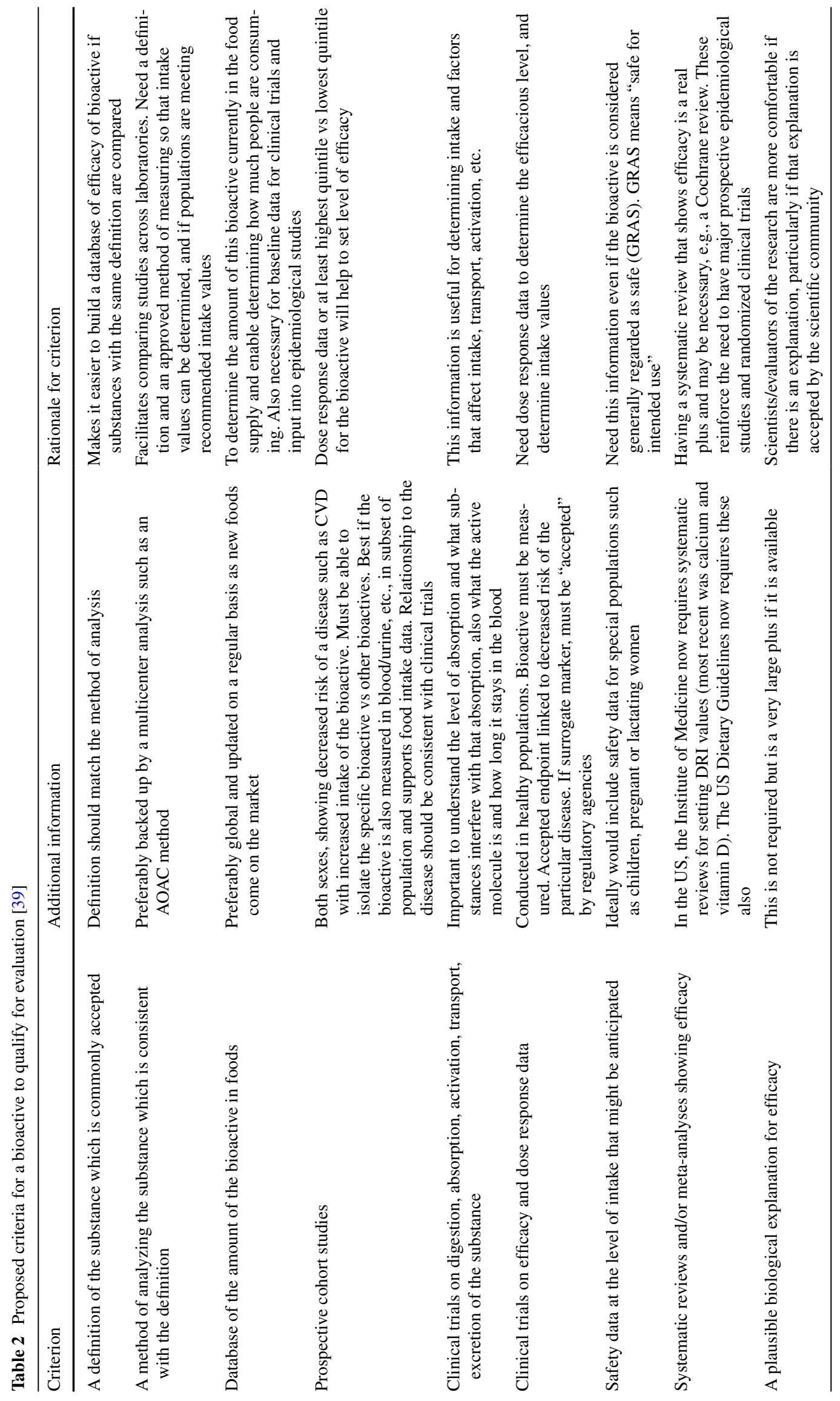


"a high standard for entrance into the evaluative process." Two years ago at this same scientific symposium, Dr. Lupton discussed potential entrance criteria as necessary information before a bioactive could be considered for a DRIlike evaluation process (see Table 2). Setting these nine criteria as essential for consideration for evaluation serves several goals: It minimizes the effort of the evaluator; and importantly, it sets a standard, if met, that investigators and funding sources could design their research to meet, knowing that there would be a certain level of credibility if they were to do so.

A consensus arose from this scientific symposium on "Nutrient Reference Values-Non-Communicable Disease Endpoints" that there is a sufficient framework and valid scientific information to begin the process of establishing DRIs (in the US/Canada) and NRV-NCDs under the auspices of Codex Alimentarius. As noted above, such a framework and the setting of numerical DRI/NRV-NCD values would be a benefit to scientists working in this field, to funders of the research, to governments, and to consumers. Such reference values would also stimulate innovation in the development of new functional foods and dietary supplements.

The goal of science is to seek truths that can be replicated. Trying to do something again and again and expecting a different outcome is linked to the definition of insanity. In a world with limited resources, and serious health and demographic challenges, if nutrients are to be considered beneficial, the scientific community needs to start asking more logical and direct questions linking observational data to mechanisms of action. Epidemiology provides clues, investigative science needs to provide hypotheses, and robust studies need to be targeted for outcomes that may be far different than that expected in pharmaceutical evaluations. To that end, we need evidence-based science to come to the rescue of this apparent dichotomy of reason within our scientific community.

Designing studies to look at endpoints based on the pharmaceutical model of efficacy when applied to dietary nutrients seems to be a difficult undertaking. First, in the area of nutritional intake or supplementation we are dealing with largely healthy populations that are not demonstrating significant disease states, whereas in clinical evaluations of novel pharmaceutical agents the study subjects by definition should be demonstrating a disease state which the novel drug is attempting to mediate or remedy. In the case of nutrients taken over long periods of time in relatively healthy populations, a different paradigm of investigation per se is required. The considerations of length of time a substance is ingested, the statistical evidence of absence of disease in these populations over time, the hypotheses of metabolism and protective value of these nutrients are all parts of a new dynamic framework of investigative science. During the symposium in Germany, a very enlightening evaluation of the myriad of studies conducted on omega-3 compounds indicated that methodologies of administration might have need of adjustment in order to appropriately consider the findings as representative of value in supplementation of these compounds.

Acknowledgments This conference report summarizes the presentations and outcomes of the meeting entitled "Nutrient Reference Value-Non-Communicable Disease (NRV-NCD) Endpoints; A Case for Both Essential and Nonessential Nutrients" held on November 20, 2015, in Kronberg im Taunus, Germany. The event was organized by the Council for Responsible Nutrition-International (www.crn-i.ch). The opinions expressed, herein, are those of the authors; this conference report is not a consensus statement; therefore, some authors may not agree with all opinions expressed.

\section{Compliance with ethical standards}

Conflict of interest J. R. Lupton, J. B. Blumberg, M. L'Abbe, A. Yaktine, and J. C. Griffiths had their travel expenses reimbursed by CNR-I. J. R. Lupton consults for Mars, Inc. J. B. Blumberg serves on scientific advisory boards for Advocare, Herbalife, Pfizer Consumer Health, Pharmavite, and SmartyPants. M. LeDoux is chairman and president of Natural Alternatives International, Inc. H. B. Rice is an employee of the Global Organization of EPA and DHA omega-3s (GOED). J. C. Griffiths is an employee of CRN-International. None of the authors declares any conflict of interest in providing their solely scientific opinion for this review.

Open Access This article is distributed under the terms of the Creative Commons Attribution 4.0 International License (http://creativecommons.org/licenses/by/4.0/), which permits unrestricted use, distribution, and reproduction in any medium, provided you give appropriate credit to the original author(s) and the source, provide a link to the Creative Commons license, and indicate if changes were made.

\section{References}

1. Aggett PJ, Hathcock J, Jukes D, Richardson DP, Calder PC, Bischoff-Ferrari H, Nicklas T, Mühlebach S, Kwon O, Lewis J, Lugard MJF, Prock P (2012) Nutrition issues at Codex: health claims, nutrient reference values and WTO agreements: a conference report. Eur J Nutr (Suppl 1):S1-S7. doi:10.1007/ s00394-012-0306-8

2. Archer E, Hand GA, Blair SN (2013) Validity of U.S. nutritional surveillance: national Health and Nutrition Examination Survey caloric energy intake data, 1971-2010. PLoS ONE 8:e76632

3. Biesalski HC, Erdman JW, Hathcock J, Ellwood K, Beatty S, Johnson E, Marchioli R, Lauritzen L, Rice HB Shao A, Griffiths J (2013) Nutrient reference values for bioactives: new approaches needed? A conference report. Eur J Nutr Suppl. doi:10.1007/s00394-013-0503-0

4. Blumberg J, Heaney RP, Huncharek M, Scholl T, Stampfler M, Vieth R, Weaver CM, Zeisel SH (2010) Evidencebased criteria in the nutritional context. Nutr Rev 68:478-484. doi:10.1111/j.1753-4887.2010.00307x

5. Burr ML, Fehily AM, Gilbert JF et al (1989) Effects of changes in fat, fish, and fibre intakes on death and myocardial reinfarction: diet and reinfarction trial (DART). Lancet 334:757-761

6. Burton-Freeman B, Talbot J, Park E, Krishnankutty S, Edirisinghe I (2012) Protective activity of processed tomato products 
on postprandial oxidation and inflammation: a clinical trial in healthy weight men and women. Mol Nutr Food Res 56:622-631

7. Calder PC (2012) Mechanisms of action of (n-3) fatty acids. J Nutr 142:592S-599S

8. Casula M, Soranna D, Catapano AL, Corrao G (2013) Longterm effect of high dose omega-3 fatty acid supplementation for secondary prevention of cardiovascular outcomes: a meta-analysis of randomized, placebo controlled trials. Atheroscler Suppl $14: 243-251$

9. CCNFSDU (CODEX COMMITTEE ON NUTRITION AND FOODS FOR SPECIAL DIETARY USES) (2014); REPORT OF THE THIRTY-SIXTH SESSION; Bali, Indonesia, 24-28 November 2014. https://www.ccnfsdu.de//fileadmin/SITE_ MASTER/content/Downloads2014/REP15_NFSDUe.pdf

10. Chen Q, Cheng LQ, Xiao TH et al (2011) Effects of omega-3 fatty acid for sudden cardiac death prevention in patients with cardiovascular disease: a contemporary meta-analysis of randomized, controlled trials. Cardiovasc Drugs Ther 25:259-265

11. Codex Alimentarius (1985) Guidelines on nutrition labelling (CAC/GL 2-1985, Rev. 2015)

12. Delgado-Lista J, Perez-Martinez P, Lopez-Miranda J, PerezJimenez F (2012) Long chain omega-3 fatty acids and cardiovascular disease: a systematic review. Br J Nutr 107:S201-S213

13. Dickinson HO, Mason JM, Nicolson DJ et al (2006) Lifestyle interventions to reduce raised blood pressure: a systematic review of randomized controlled trials. J Hypertens 24:215-233

14. EFSA Panel on Dietetic Products, Nutrition and Allergies (2012) Scientific opinion related to the tolerable upper intake level of eicosapentaenoic acid (EPA), docosahexaenoic acid (DHA) and docosapentaenoic acid (DPA). EFSA J 10:2815

15. Engelhard YN, Gazer B, Paran E (2006) Natural antioxidants from tomato extract reduce blood pressure in patients with grade-1 hypertension: a double-blind, placebo-controlled pilot study. Am Heart J 151(100):e101-e106

16. Food and Agriculture Organization (FAO) of the United Nations/ World Health Organization (WHO) (2006) A model for establishing upper levels of intake for nutrients and related substances report of a joint FAO/WHO technical workshop on nutrient risk assessment. WHO headquarters, Geneva, Switzerland

17. Food and Agriculture Organization (FAO) of the United Nations (2010) Fats and fatty acids in human nutrition: report of an expert consultation. FAO food and nutrition paper 91. Rome

18. Fraga CG, Oteiza PI (2011) Dietary flavonoids: role of (-)-epicatechin and related procyanidins in cell signaling. Free Radic Biol Med 51:813-823

19. Galan P, Kesse-Guyot E, Czernichow S et al (2010) Effects of B vitamins and omega 3 fatty acids on cardiovascular diseases: a randomised placebo controlled trial. BMJ 341:c6273

20. GISSI-HF Investigators, Tavazzi L, Maggioni AP et al (2008) Effect of $n-3$ polyunsaturated fatty acids in patients with chronic heart failure (the GISSI-HF trial): a randomised, double-blind, placebo-controlled trial. Lancet 372:1223-1230

21. GISSI-Prevenzione Investigators (1999) Dietary supplementation with n-3 polyunsaturated fatty acids and vitamin $\mathrm{E}$ after myocardial infarction: results of the GISS-Prevenzione trial. Lancet 354:447-455

22. Harris WS (2013) Are n-3 fatty acids still cardioprotective? Curr Opin Clin Nutr Metab Care 16:141-149

23. IOM (Institute of Medicine) (1994) How should the recommended dietary allowances be revised? National Academy Press, Washington, DC

24. IOM (Institute of Medicine) (2005) Dietary reference intakes for energy, carbohydrate, fiber, fat, fatty acids, cholesterol, protein and amino acids (Macronutrients). National Academies Press, Washington, DC
25. IOM (Institute of Medicine) Committee on Qualification of Biomarkers and Surrogate Endpoints in Chronic Disease (2011) Perspectives on biomarker and surrogate endpoint evaluation: discussion forum summary. National Academies Press, Washington, DC

26. James MJ, Sullivan TR, Metcalf RG et al (2014) Pitfalls in the use of randomised controlled trials for fish oil studies with cardiac patients. Br J Nutr 112:812-820

27. Kay CD, Hooper L, Kroon PA, Rimm EB, Cassidy A (2012) Relative impact of flavonoid composition, dose and structure on vascular function: a systematic review of randomised controlled trials of flavonoid-rich food products. Mol Nutr Food Res 56:1605-1616

28. Kim JY, Paik JK, Kim OY, Park HW, Lee JH, Jang Y, Lee JH (2011) Effects of lycopene supplementation on oxidative stress and markers of endothelial function in healthy men. Atherosclerosis 215:185-195

29. Köbe T, Witte AV, Schnelle A, Lesemann A, Fabian S, Tesky VA, Pantel J, Flöel A (2015) Combined omega-3 fatty acids, aerobic exercise and cognitive stimulation prevents decline in gray matter volume of the frontal, parietal and cingulate cortex in patients with mild cognitive impairment. Neuroimage. doi:10.1016/j. neuroimage.2015.09.050

30. Köhler A, Bittner D, Löw A, von Schacky C (2010) Effects of a convenience drink fortified with n-3 fatty acids on the n-3 index. Br J Nutr 104:729-736

31. Kokubo $\mathrm{Y}$, Iso $\mathrm{H}$, Ishihara J, Okada K, Inoue M, Tsugane S (2007) Association of dietary intake of soy, beans, and isoflavones with risk of cerebral and myocardial infarctions in Japanese populations: the Japan Public Health Center-based (JPHC) study cohort I. Circulation 116:2553-2562

32. Kotwal S, Jun M, Sullivan D et al (2012) Omega 3 Fatty acids and cardiovascular outcomes: systematic review and meta-analysis. Circ Cardiovasc Qual Outcomes 5:808-818

33. Kromhout D, Giltay EJ, Geleijnse JM, for the Alpha Omega Trial Group (2010) n-3 fatty acids and cardiovascular events after myocardial infarction. N Engl J Med 363:2015-2026

34. Kwak SM, Myung SK, Lee YJ et al (2012) Efficacy of omega-3 fatty acid supplements (eicosapentaenoic acid and docosahexaenoic acid) in the secondary prevention of cardiovascular disease: a meta-analysis of randomized, double-blind, placebo-controlled trials. Arch Intern Med 172:686-694

35. Langlois K, Ratnayake WMN (2015) Omega-3 index of canadian adults. Statistics Canada, catalogue no. 82-003-X. Health Rep 26:3-11

36. LeDoux MA, Appelhans KR, Braun LA, Dziedziczak D, Liu L, Osiecki H, Wyszumiala E, Griffiths JC (2015) A quality dietary supplement: before you start and after it's marketed-a conference report. Eur J Nutr. doi:10.1007/s00394-014-0827-4

37. León H, Shibata MC, Sivakumaran S et al (2008) Effect of fish oil on arrhythmias and mortality: systematic review. BMJ 337:a2931

38. Lim SS, Vos T, Flaxman AD et al (2012) A comparative risk assessment of burden of disease and injury attributable to 67 risk factors and risk factor clusters in 21 regions, 1990-2010: a systematic analysis for the Global Burden of Disease Study 2010. Lancet 380:2224-2260

39. Lupton JR, Atkinson SA, Chang N, Fraga CG, Levy J, Messina M, Richardson DP, van Ommen B, Yang Y, Griffiths JC, Hathcock J (2014) Exploring the benefits and challenges of establishing a DRI-like process for bioactives. Eur J Nutr Suppl. doi:10.1007/s00394-014-0666-3

40. Macchia A, Grancelli H, Varini S et al (2013) Omega-3 fatty acids for the prevention of recurrent symptomatic atrial fibrillation: results of the FORWARD(Randomized Trial to Assess 
Efficacy of PUFA for the Maintenance of Sinus Rhythm in Persistent Atrial Fibrillation) trial. J Am Coll Cardiol 61:463-468

41. Marchioli R, Levantesi G (2013) n-3 PUFAs in cardiovascular disease. Int J Cardiol 170:S33-S38

42. Marik PE, Varon J (2009) Omega-3 dietary supplements and the risk of cardiovascular events: a systematic review. Clin Cardiol 32:365-372

43. Miller PE, Van Elswyk M, Alexander DD (2014) Long-chain omega-3 fatty acids eicosapentaenoic acid and docosahexaenoic acid and blood pressure: a meta-analysis of randomized controlled trials. Am J Hypertens 27:885-896

44. Mitre Corporation (1989) Health effects of refined menhaden oil. National Technical Information Service, order no. PB89-182398

45. Murphy SP (2008) Using DRIs as the basis for dietary guidelines. Asia Pac J Clin Nutr 17:52-54

46. NRC (National Research Council) (1989) Diet and Health: Implications for Reducing Chronic Disease Risk. National Academy Press, Washington, DC

47. Norwegian Scientific Committee for Food Safety (VKM) (2011) Evaluation of negative and positive health effects of $n-3$ fatty acids as constituents of food supplements and fortified foods. ISBN: 978-82-8082-365-6. http://www.vkm.no/dav/c7a41adb79. pdf

48. Office of Disease Prevention and Health Promotion, Office of Public Health and Science, Department of Health and Human Services (2004) Solicitation of written comments on proposed definition of bioactive food components. Fed Regist 69:55821-55822

49. ORIGIN Trial Investigators, Bosch J, Gerstein HC et al (2012) n-3 fatty acids and cardiovascular outcomes in patients with dysglycemia. N Engl J Med 367:309-318

50. Paran E, Novack V, Engelhard YN, Hazan-Halevy I (2009) The effects of natural antioxidants from tomato extract in treated but uncontrolled hypertensive patients. Cardiovasc Drugs Ther 23:145-151

51. Plourde M, Cunnane SC (2007) Extremely limited synthesis of long chain polyunsaturates in adults: implications for their dietary essentiality and use as supplements. Appl Physiol Nutr Metab 32:619-634

52. Rauch B, Schiele R, Schneider S et al (2010) OMEGA, a randomized, placebo-controlled trial to test the effect of highly purified omega- 3 fatty acids on top of modern guideline-adjusted therapy after myocardial infarction. Circulation 122:2152-2159

53. Risk and Prevention Study Collaborative Group, Roncaglioni MC, Tombesi M et al (2013) n-3 Fatty Acids in Patients with Multiple Cardiovascular Risk Factors. N Engl J Med 368:1800-1808

54. Rizos EC, Ntzani EE, Bika E et al (2012) Association between omega-3 fatty acid supplementation and risk of major cardiovascular disease events: a systematic review and meta-analysis. JAMA 308:1024-1033

55. Shao A (2009) Evidence based nutrition. The World of Food Ingredients Oct/Nov 103-105

56. Shao A, MacKay D (2010) A commentary on the nutrientchronic disease relationship and the new paradigm of evidencebased nutrition. Nat Med J 2:10-18

57. Smith GI, Julliand S, Reeds DN, Sinacore DR, Klein S, Mittendorfer B (2015) Fish oil-derived n-3 PUFA therapy increases muscle mass and function in healthy older adults. Am J Clin Nutr 102:115-122

58. Somogyi A, Hathcock J, Biesalski HK, Blumberg JB, Antoine JM, Edwards G, Prock P (2011) Scientific issues related to
Codex Alimentarius goals: a review of principles with examples. Reg Toxicolo Pharmacol 60:161-164

59. Strand E, Pedersen ER, Svingen GF et al (2013) Dietary intake of n-3 long-chain polyunsaturated fatty acids and risk of myocardial infarction in coronary artery disease patients with or without diabetes mellitus: a prospective cohort study. BMC Med 11:216

60. Taku K, Melby MK, Kronenberg F, Kurzer MS, Messina M (2012) Extracted or synthesized soybean isoflavones reduce menopausal hot flash frequency and severity: systematic review and meta-analysis of randomized controlled trials. Menopause 19:776-790

61. Trikalinos TA, Lee J, Moorthy D et al (2012) Effects of eicosapentanoic acid and docosahexanoic acid on mortality across diverse settings: systematic review and meta-analysis of randomized trials and prospective cohorts. In: Technical review 17, vol 4. (Prepared by the Tufts Medical Center Evidence-based Practice Center under Contract No. HHSA 290-2007-10055-1.) AHRQ Publication No. 12-EHC040-EF. Agency for Healthcare Research and Quality, Rockville, MD

62. U.S. Dhhs (Department of Health and Human Services) (1988) Public Health Service. The Surgeon General's Report on Nutrition and Health, US Government Printing Office, Washington, DC

63. van der Wurff ISM, von Schacky C, Berge K, Zeegers MP, Kirschner PA, de Groot RHM (2016) Positive association between blood Omega-3 index and cognition in healthy Dutch adolescents. Nutrients $8: 1$

64. von Schacky C (2015) Omega-3 fatty acids in cardiovascular disease-an uphill battle. Prostaglandins Leukot Essent Fatty Acids 92:41-47

65. Wagner JA, Ball JR (2015) Implications of the institute of medicine report: evaluation of biomarkers and surrogate endpoints in chronic disease. Clin Pharmacol Ther 98(1):12-15

66. Wen YT, Dai JH, Gao Q (2014) Effects of Omega-3 fatty acid on major cardiovascular events and mortality in patients with coronary heart disease: a meta-analysis of randomized controlled trials. Nutr Metab Cardiovasc Dis 24:470-475

67. Witte AV, Kerti L, Hermannstädter HM, Fiebach JB, Schreiber SJ, Schuchardt JP, Hahn A, Flöel A (2014) Long-chain omega-3 fatty acids improve brain function and structure in older adults. Cereb Cortex 24:3059-3068

68. Wu AH, Yu MC, Tseng CC, Pike MC (2008) Epidemiology of soy exposures and breast cancer risk. Br J Cancer 98(1):9-14. doi:10.1038/sj.bjc.6604145

69. Wu JH, Mozaffarian D (2014) Omega-3 fatty acids, atherosclerosis progression and cardiovascular outcomes in recent trials: new pieces in a complex puzzle. Heart 100:530-533

70. Yokoyama M, Origasa H, Matsuzaki M et al (2007) Japan EPA lipid intervention study (JELIS) Investigators, Effects of eicosapentaenoic acid on major coronary events in hypercholesterolaemic patients (JELIS): a randomized open-label, blinded endpoint analysis. Lancet 369:1090-1098

71. Zaalberg A, Wielders J, Bulten E, van der Staak C, Wouters A, Nijman H. (2015) Relationships of diet-related blood parameters and blood lead levels with psychopathology and aggression in forensic psychiatric inpatients. Crim Behav Ment Health. doi: $10.1002 / \mathrm{cbm} .1954$

72. Zhao YT, Chen Q, Sun YX et al (2009) Prevention of sudden cardiac death with omega-3 fatty acids in patients with coronary heart disease: a meta-analysis of randomized controlled trials. Ann Med 41:301-310 